\title{
iSchools \& the iSchool at Syracuse University
}

\author{
Elizabeth D. Liddy
}

\begin{abstract}
An overview of the origin, development, and current status of the iSchool movement - both the organization which began as the iSchool Caucus, which now leads the much larger iSchool Organization, as well as the profile of one particular iSchool - the School of Information Studies at Syracuse University, in Syracuse, New York. As the rate of change in who, how, when, and where information is being sought and produced is both evolving and accelerating, along with the need for reliable, high quality information, the demands on the information professions are both challenging and exciting. Today, the iSchool Organization is comprised of 55 leading iSchools, from 17 countries, spanning 4 continents, and is actively working with additional top-ranked Schools of Library and/or Information Science in multiple other universities and countries who are interested in joining. The iSchool at Syracuse, which was one of the original members of "Gang of Three" that conceived of a membership organization to promote the information profession, is presented with detail on programs, particularly their most recent focuses on social media, data science, and information entrepreneurship.
\end{abstract}

Keywords iSchool Caucus $\cdot$ iSchools $\cdot$ Syracuse University $\cdot$ School of Information Studies

It is a truly exciting time for those involved in the library and information science fields, as it is increasingly recognized in every quarter how important the information professions are. The rate of change in all endeavors is accelerating, along with the reliance on high quality information, and as a result, the demands on our profession are both challenging and exciting.

Elizabeth D. Liddy is Dean and Trustee Professor in the iSchool at Syracuse University. Liddy is the founding president of TextWise LLC, and founding Director of the Center for Natural Language Processing. Liddy has led 70 re-search projects, authored more than 110 research papers, and is the holder of 8 software patents. Liddy was the 2012-2013 Chair of the iSchool Caucus. Email: liddy@syr.edu

\footnotetext{
E. D. Liddy $(\bowtie)$

Syracuse University, Syracuse, USA

e-mail: liddy@syr.edu

C. Chen, R. Larsen (eds.), Library and Information Sciences,

DOI 10.1007/978-3-642-54812-3 4, (C) The Author(s) 2014
} 
In this era of rising prominence, it is important that we in the education of library and information science professionals share our experiences from around the world - that we learn from each other-so that we can respond in optimal ways to increasingly global demands, and further raise the recognition of the world's overwhelming reliance on information and the information professions.

\section{The iSchool Movement}

An initial and natural response to this need for cooperation has been what is termed the 'iSchool Movement' which began in the late 1980s when deans of schools in United States universities who offer degrees in library and/or information science started meeting informally for the purpose of building a strong, unified coalition of schools that are interested in strengthening the relationships between information, technology, and people. This group of deans has since come to be called the "iSchool Caucus" (caucus is defined as a meeting of people with the same goal of bringing about organizational change) and formally adopted its charter in July, 2005. Today, the iCaucus consists of 55 leading iSchools, from 17 countries, spanning 4 continents, and is now actively working with top-ranked Schools of Library and/or Information Science in multiple other countries who are interested in joining. Member schools must have substantial sponsored research activity, be engaged in the training of future researchers via Ph.D. programs, and be visionary in their views of the role of information in the world of the future.

The iSchool Caucus has enabled its member schools to jointly create a common image and message, which is particularly needed by schools which have an undergraduate program that students enter at the age of 18 , when they themselves are not yet really sure what career they want to pursue, and do not necessarily think of the information field as a profession. On the other hand, Masters students entering the graduate programs recognize the importance of information and know what they want to be when they graduate - either librarians of one type or another, or managers of the Information Technology (IT) infrastructure in a large organization, or perhaps managers of large telecommunication projects.

The current members of the iSchool Organization, which includes the iCaucus are: Carnegie Mellon University, Charles Sturt University, Drexel University, Florida State University, Georgia Tech, Humboldt University, Indiana University, Michigan State University, Nanjing University, Northumbria University, NOVA University, Open University of Catalonia, Pennsylvania State University, Polytechnic University of Valencia, Rutgers, Seoul National University, Singapore Management University, Sungkyunkwan University, Syracuse University, Télécom Bretagne, University College Dublin, University College London, University of Amsterdam, University of Boras, University of British Columbia, UC Berkeley, UC Irvine, UCLA, University College: Oslo and Akershus University of Copenhagen, University of Glasgow, University of Illinois, University of Kentucky, University of Maryland-College Park, University of Maryland-Baltimore County, University 
of Melbourne, University of Michigan, University of Missouri, University of North Carolina, University of North Texas, University of Pittsburgh, University of Porto, University of Sheffield, University of Siegen, University of South Australia, University of Strathclyde, University of Tampere, University of Tennessee, University of Texas-Austin, University of Toronto, University of Tsukuba, University of Washington, University of Wisconsin-Madison, University of Wisconsin-Milwaukee, and Wuhan University.

Some iSchools grew out of Library Science Schools, some out of Computer Science Schools, some have merged with Communication Departments, some have merged with Management-but the telling characteristic of each is that they are interdisciplinary and all share the same goal - to enable their graduates to become successful professionals based on their combined expertise in information, technology, and management. As the figure here shows, graduates of the iSchools are prepared to assume positions in organizations in professional roles spanning both the technical and managerial aspects of information provision.

\section{Bridging Management and Technology}

\section{Technical Positions}

Traditional Technical

Careers BS or MS - ComputerScience

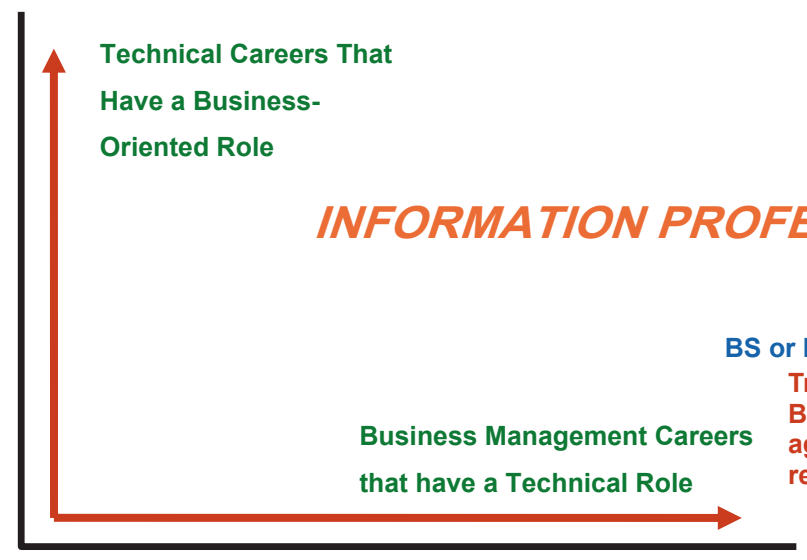

BS or MBA - Management

Traditional

Business Man-

agement $\mathrm{Ca}$ -

reers

Executive Positions

\section{Entry Level}

Presented quite broadly, the goals of the iCaucus are to work on behalf of its member schools to raise awareness of the Information Field amongst student prospects, the business community, the media, funders of research, and users of information. Members of the iCaucus are able to broaden their course offerings to students via distance education courses available through the WISE Consortium, wherein students can take courses offered at other member schools while paying their own local tuition and receiving credit at their home university. 
In addition, the iCaucus sponsors an annual iConference that is open to all schools, faculty, and students, not just iCaucus members, and provides opportunities for presentation and sharing of research and teaching in the field of information. The $9^{\text {th }}$ iConference was held in Berlin, Germany in March, 2014. Ongoing sessions of interest at the iConference include how the iSchool Movement is expanding internationally.

\section{The iSchool at Syracuse}

We now move from the topic of the field of iSchools to focus on how one particular school - the iSchool at Syracuse University-fulfills the iSchool mission. The iSchool at Syracuse University was founded in 1896 as the School of Library Science, and the school focused on educating students in librarianship for its first 78 years. Then, in 1974, Dean Robert Taylor changed the name to the School of Information Studies. Syracuse was the first school to recognize that information was of significance in organizations other than libraries, was the first to adopt 'Information' in its name, and is therefore rightfully called The Original Information School ${ }^{\mathrm{TM}}$ and has served over time as a model for an increasing number of emerging iSchools.

The iSchool at Syracuse is guided by the core values articulated by our faculty that emanate from our visionary goal "To expand human capabilities through information." Our beliefs are that "Through information we transform individuals, organizations, and society." And "We recognize that information technology and management processes are means and not ends."

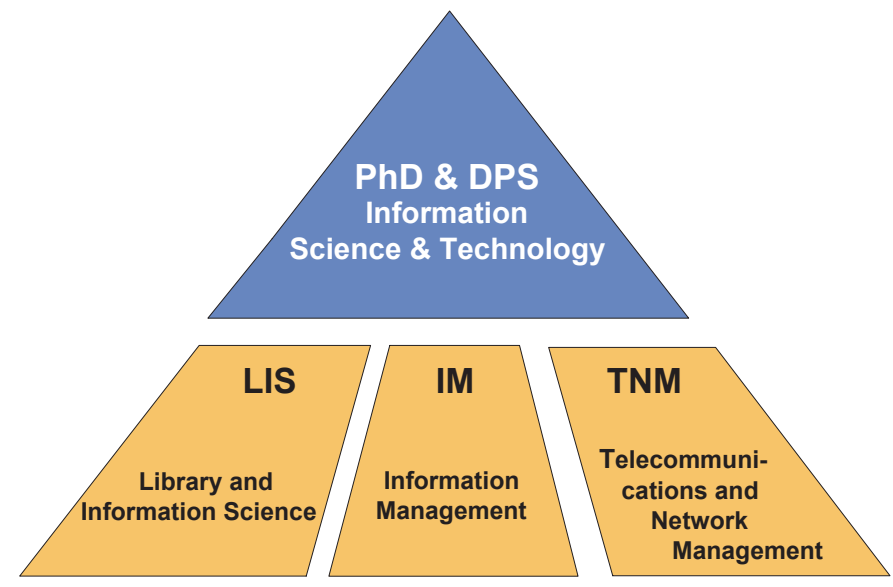

\section{BS in Information Management and Technology} BS in Systems \& Information Science 
The iSchool at Syracuse currently has 7 degree programs - a unique combination of academic offerings and research foci that provide diversity-but a unified diversity. The three masters programs reflect the rich, complex range of capabilities our students learn-Library \& Information Science, Information Management, and Telecommunications \& Network Management. These degrees are offered via both onsite and online delivery modes, having been teaching online for 20 years, with $30 \%$ to $40 \%$ of the masters degrees now being earned online. The Doctor of Professional Studies in Information Science and Technology is now available for information professionals seeking to earn the next level degree, without the need to leave their current position, while receiving credit for the learnings they have gained from their professional experiences. This new offering fits with the iSchool at Syracuse's commitment to life-long learning and meeting the evolving needs of students at various stages of their professional careers.

Currently, the iSchool at Syracuse has approximately 670 undergraduate students, 700 masters students, and 70 doctoral students. Our students are of the highest quality and many are attracted to the iSchool at Syracuse by the high national rankings of our programs. The standard reference for masters programs is the U.S. News \& World Report, which ranks Syracuse as \#1 in Information Systems, \#2 in Digital Libraries, \#3 in Library and Information Science schools, and \#4 in School Media.

\section{Faculty of One Overview}

The iSchool has a balanced commitment to scholarship, teaching, and research that attracts the finest scholars in the world. Our interdisciplinary faculty of 53 full-time members collaborate with colleagues across fields of study and readily partner with global communities of experts to expand the boundaries of exploration in the information field.

Faculty members consider themselves a "faculty of one," with no traditional departments dividing their interactions or their teaching and research activities. The school's collegial atmosphere encourages intellectual inquiry and lifelong learning among faculty and students. Our faculty serve as role models for students and challenge them to develop into independent thinkers, problem solvers, and architects of a better world.

\section{Three Recent Focuses at Syracuse's iSchool}

\section{Information Entrepreneurship}

The culture at the School of Information Studies is steeped in entrepreneurship, which at the iSchool encompasses both the traditional goal of creating startups and the forward-thinking skills to implement social change. From entrepreneurial 
faculty to student startups, the environment encourages students to explore their entrepreneurial spirit through several programs and curriculum opportunities.

In the classroom, two courses, What's the Big Idea and Idea to Startup, provide a framework for students to acquire the basic knowledge and skills required to run a successful business. Students also learn how to develop and refine new ideas - and turn those ideas into a viable venture.

The iSchool is a sponsor of the Syracuse Student Sandbox, a unique business incubator that gives aspiring student entrepreneurs the resources to make their visions a reality. The Sandbox's goal is to accelerate the process of ideation, development, and deployment through mentoring and coaching. Through a 12-week, experientialbased program, participants are expected to reach an end goal of producing revenue generating entities or investment-ready firms. Culminating in a "Demo Day," the Student Sandbox Program provides coaching, mentoring, educational programming, physical space, access to subject matter experts, and investors. A full-time entrepreneur-in-residence guides teams through the program and serves as a coach and conduit to the entrepreneurship community.

\section{Data Science}

As the amount of data in the world grows in variety, volume, and velocity, organizations need professionals who can collect, manage, curate, analyze, and visualize data to make better decisions and add value to their organizations. Experts predict a major skills gap over the next five to 10 years in data science and the Syracuse iSchool is preparing students to meet this critical, professional demand.

In 2011, the iSchool began offering the first New York State-approved Certificate of Advanced Study (CAS) in Data Science. The iSchool's interdisciplinary faculty developed an industry-relevant curriculum that allows graduate students from a wide array of educational and professional backgrounds to learn to bridge the gap between technical specialists who work directly with IT infrastructure and senior leadership who use data to lead organizations.

With a foundation in information management, digital curation, visualization, and analytics, the certificate in Data Science provides students with a comprehensive understanding of the full data lifecycle. While technical skills are an important component of the curriculum, graduates are also equipped with communication and leadership skills that will carry them far beyond the rise and fall of any one data analysis technology.

\section{Social Media/Emerging Technologies}

Social media and emerging technologies (such as Internet-connected devices and location-based technology) make it possible for people to access and share information in real time with their networks. This development has shifted how 
organizations of all types leverage information internally and externally. In some cases, this reality has introduced entirely new information challenges, thereby creating a need for professionals who understand social media technologies, their capabilities, and their applications in the enterprise.

Through new coursework and the development of the New Explorations in Information and Science (NEXIS) laboratory at the iSchool, students have the opportunity to learn first-hand how to manage information in the enterprise, and build tools and solutions to curate information and data from various sources, in real time.

\section{Conclusion}

As can be seen from the details above, both the status of the iSchools Organization as a whole, and the iSchool at Syracuse University in particular, our professional field has flourished and is poised for even greater growth and prominence-particularly as our international partnerships increase. As many have said, for a good number of years now, this is the Information Age, and the iSchools stand ready to lead in both the research essential for the advancement of the field, and in the education of information professionals to provide leadership.

Open Access This chapter is distributed under the terms of the Creative Commons Attribution Noncommercial License, which permits any noncommercial use, distribution, and reproduction in any medium, provided the original author(s) and source are credited. 